\title{
CITIZENS OF THE ACADEMIC COMMUNITY? A SOCIETAL PERSPECTIVE ON LEADERSHIP IN UK HIGHER EDUCATION
}

Richard Bolden $^{\mathrm{a}^{*}}$, Jonathan Gosling ${ }^{\mathrm{a}}$ and Anne O’Brien ${ }^{\mathrm{a}}$

${ }^{a}$ Centre for Leadership Studies, University of Exeter Business School, Exeter, UK

* Contact author: Richard.Bolden@exeter.ac.uk

\section{Acknowledgements}

We would like to express our gratitude to the LFHE for funding this work and, in particular, Robin Middlehurst and Helen Goreham for their support and guidance. We would also like to acknowledge the contribution of our colleagues Michelle Ryan, Kim Peters and Alex Haslam in the University of Exeter School of Psychology, as well as Jonathan Wyatt of the Oxford Learning Institute who helped arrange the listening posts. We are very grateful to the participants in our study, whose thoughtful contributions and generosity with their time is much appreciated.

Accepted for Publication in Studies in Higher Education, 03/10/2012 


\title{
CITIZENS OF THE ACADEMIC COMMUNITY? A SOCIETAL PERSPECTIVE ON LEADERSHIP IN UK HIGHER EDUCATION
}

\begin{abstract}
This paper presents a societal perspective on academic leadership by exploring the preoccupations of academics as citizens rather than as employees, managers or individuals. It uses a Listening Post methodology to ask 'what is it like to be a citizen of an academic institution in contemporary Britain?' Three listening posts, comprising 26 participants from 15 higher education institutions, were conducted and analysed. A number of common themes were identified, including a sense of ambiguity and ambivalence about one's relationship with the employing institution and a concern about the fragmentation of academic identities. Whilst this paper contributes towards debates about the marketisation of higher education and the implications for leadership and management practice, its main contribution is to challenge dominant individual and organisational perspectives on leadership by exposing an alternative discourse, based on citizenship, which may offer new opportunities for engagement in the civic life of universities.
\end{abstract}




\section{Introduction}

This paper considers the relationship between citizenship and leadership in higher education (HE). It explores a sub-set of findings from a larger project (authors, 2012) which investigated how UK-based academics conceive of 'academic leadership' and the impact of these conceptions on leadership-related attitudes and behaviours. The larger study comprised three main data collection methods: survey, listening posts and interviews. In this paper we focus specifically on the listening posts and their implications for taking a societal perspective on leadership in and of academia.

Listening posts are a methodology developed from the systems psychodynamic approach of the Tavistock Institute for Human Relations and subsequently refined and applied by OPUS (an Organization for Promoting Understanding of Society) as a means for investigating the preoccupations of citizens in society (Dartington, 2000). This methodology was employed within the current study in an attempt to explore the hopes, concerns and experiences of UK academics at a collective level, rather than as individuals or members of a particular professional group or organisation. The discourse of citizenship was invoked as an alternative to leadership or management in order to encourage participants to reflect on their membership of higher education in the broadest sense. By responding as 'citizens' they were invited to engage in ways that were not defined or constrained by the roles they held and/or the institution in which they worked. Participants described a sense of ambiguity and ambivalence about their relationship with their employing institutions and a concern about the fragmentation of academic identities that have implications for how the leadership and management of academic work is conceived, accomplished and sustained. This paper contributes to the literature on academic leadership by taking a societal perspective which complements individual and organisational accounts that dominate the field and offers a 
methodology through which such analyses are made possible. It concludes with recommendations for future research and practice.

\section{Leadership and citizenship in higher education}

Recent years have seen substantial changes in higher education in the UK (as elsewhere) in response to factors such as increasing participation rates, internationalisation, funding, policy and market competition (Deem et al., 2007, Molesworth et al., 2011). Such changes have challenged traditional assumptions on the nature and purpose of HE, as well as its place in society (Bargh et al., 1996, Beverungen et al., 2008, Khurana, 2007). Throughout this period of change, it has been argued, there has been a general shift away from 'collegial' towards more 'corporate', 'entrepreneurial' or 'managerial' approaches to leadership and management (Clark, 1998, Henkel, 1997, McNay, 1995) informed by private sector practices. Whilst a 'business like' approach to running universities may be understandable given the size and budgets of these organisations and the competitive environment in which they operate, the utilitarian ethos that underpins such an approach may be experienced as conflicting with the normative values traditionally associated with academic work (Albert and Whetten, 2004, Macfarlane, 2005). To this extent emerging forms of leadership and management practice may be experienced as conflicting with ideals of collegiality, academic freedom, education and scholarship, ultimately distancing and disengaging the very people that universities seek to influence and involve in institutional governance, strategy and change.

Despite the growth of interest in leadership in HE, as a field of research as well as practice, attention to date has focussed almost exclusively on the role, capabilities and experiences of people with formal managerial responsibilities on behalf of their institution and their contribution towards functions and processes linked to individual and organisational performance (see, for example, Bryman, 2007, Middlehurst, 2008, Goodall, 2009). Whilst 
recent work, such as Macfarlane (2011, 2012) and Rayner et al. (2010), has called for consideration of the role played by professors in 'intellectual leadership' more broadly their continued focus on those in positions of seniority and power may underplay the prevalence and significance of informal and emergent leadership both within and beyond the institution.

Whilst we do not question the importance of existing work in this field, we suggest it addresses only a relatively small proportion of possible factors related to the leadership of academic work. In particular, we argue, current literature on leadership in HE focuses almost exclusively at individual and organisational levels, with only limited recognition of broader social and cultural processes (Bolden et al., 2008, 2009). The predominance of research with formal role holders equates 'academic leadership' with the leadership of academic institutions - thereby reinforcing the view that 'academic leadership' is what is done by vice chancellors, deans, heads of department, professors, etc., and best assessed in terms of its contribution towards organisational outcomes. It remains wedded to the 'tripod' ontology of leaders, followers and shared goals as the defining features of leadership (Bennis, 2007, cited in Drath et al., 2008) with little consideration of the underlying systemic processes that may produce the outcomes of direction, alignment and commitment so often associated with effective leadership (Drath et al., 2008).

In this paper we take a social process perspective on leadership (Uhl-Bien, 2006, Cunliffe and Eriksen, 2011) in which it is considered to be relationally constructed and embedded within communities. We use the concept of citizenship as an alternative to the discourses of leadership and management for a number of reasons. Firstly, in its broadest sense the term 'citizen' refers to someone who can be considered as a member of a recognisable social, cultural, political, national, organisational and/or professional community. Secondly, citizenship implies a set of rights and responsibilities associated to 
one's membership of that community. And thirdly, the notion of citizenship carries particular significance in higher education given the concept of 'academic citizenship'.

Macfarlane (2005) cites the three dimensions of citizenship identified by Marshall and Bottomore (1992) as particularly pertinent within universities. These dimensions (political literacy, community involvement, and social and moral responsibility) he argues are fundamental aspects of academic work yet have been largely sidelined in recent policy and reform. The service aspect of academic citizenship, he suggests "constitute[s] the "glue" that keeps academic communities and the universities they work in going and connected to the world around them. [...] Yet', he continues 'in the conceptualisation of academic life, the role of service has been, by and large, overlooked or trivialised as little more than "administration" rather than essential to the preservation of community life' (Macfarlane, 2005: 299).

The decreasing importance placed on citizenship in HE is by no means limited to the UK. Milton Greenberg (2006), for example, bemoaned the closure of the American Association for Higher Education (AAHE) as a sad indictment of the profession and evidence of the lack of attention given to 'teaching, student life, general education, and the academy's responsibility to a changing nation and world' (ibid: B20). Academic citizenship, it seems, has become sidelined by organisational concerns about financial performance, research output, workload allocation, student recruitment and institutional ranking, that may undermine commitment to the wider communities that universities, and the academics within them, serve (Macfarlane, 2007).

Thompson et al. (2005) suggest that core academic rights and responsibilities include: self-governance and self-regulation, academic freedom and tenure, and self-directedness. These rights, however, carry a commitment to undertake certain duties, including: serving on governance bodies, maintaining competence, mentoring, leadership, and promoting the 
welfare of the collective. Hence, it is suggested that whilst self-governance is a core academic right it brings an obligation to engage actively in governance and leadership of the academic community. As the authors suggest:

'[Leadership] is an ongoing responsibility of citizenship and it occurs in all aspects of one's university life since some changes are as local as introducing or promoting pedagogical opportunities and others as large as changing social priorities and conditions. Some can only be responded to by instructors in the context of individual classes, others require the involvement of large numbers of faculty (curricular revision, for example), and yet others require extra-university activities such as negotiating government-university frameworks.' (ibid: 134)

Academic freedom and academic duty therefore may be considered as two sides of the same coin (Kennedy, 1997, cited in Macfarlane, 2005) yet the reported experience of academics in recent years seems to be one of increasing disengagement and dissociation from the decision making processes that affect them and the profession (Bolden et al., 2009, Macfarlane, 2011). In this paper we use a Listening Post methodology and the notion of citizenship in order to explore the preoccupations of academic staff within UK universities from a non-managerial, organisational or role-specific perspective.

\section{Methodology}

As indicated in the introduction, the Listening Post ${ }^{\mathrm{i}}(\mathrm{LP})$ method was developed out of the system psychodynamic approach of the Tavistock Institute of Human Relations in order to explore the concept of 'citizenship in the workplace' (Lawrence, 1980). More recently this approach has been developed by OPUS in order to gain a broader understanding of the 'preoccupations' of citizens in contemporary society (Dartington, 2000). The aims and assumptions are described as follows: 
'The aim of the listening post is to enable participants as individual citizens to reflect on their own relatedness to society and to try to develop an understanding of what is happening in society at any given moment [... They] provide an opportunity for participants to share their preoccupations in relation to the various societal roles they may have [...] The dynamics of the group may be such that even a small group may nevertheless act as if it is a microcosm of the large group that is society. So that, the themes that emerge through associative dialogue may legitimately be analysed for their societal content.' (OPUS, 2010)

It was with a similar logic that we chose to use this approach to explore the experiences and preoccupations of academics within UK higher education in order to better understand the dynamics of change and the competing, contested and contrasting experiences, expectations and aspirations of staff within the sector. In particular, this approach was chosen because of its potential to surface the collective (and possibly unconscious) assumptions, hopes, anxieties and desires of members of this population in a way that more structured and individually-orientated surveys and interviews would be unlikely to reveal.

Typically LPs include 8-15 people who are invited on the basis of their membership of a particular community or society (OPUS, 2010). Participation is voluntary and may involve attendance at a number of events. Whilst attempts may be made by the organisers to ensure representation from a cross-section of society the concept of a truly 'representative' sample is unrealistic and not a primary objective given that the aim is to use the collective experience of the group to reflect on trends and issues in society. As Khaleelee and Miller (1985) explain, it uses the power of the group to explore and reflect upon societal concerns. Where LPs differ from focus groups is in the nature of questioning, the structuring of discussion and the role of the facilitator. Whilst focus groups are designed to collect insights 
related to a specific issue, usually determined in advance by the researcher/facilitator, LPs are framed more broadly and seek to encourage free associative dialogue, allowing participants to pursue and explore issues as they emerge. In terms of structure and process, focus groups begin with an introduction to the issue following which the facilitator's role is to take notes, encourage discussion and to ensure that the conversation does not stray too far from the topic of debate. In a focus group the researcher would not usually be an active participant but rather the person to gather, collate and interpret the views and opinions of participants. In a listening post only minimal introduction and framing is given to the conversation. Once discussion begins, the facilitator becomes an active member of the group, reflecting on their own relatedness to society in the same way as other participants. Whilst they may have a responsibility for taking notes and documenting the process, it is important that this is done subtly and does not interfere with group processes and the willingness of participants to engage in conversation. The facilitator in a listening post needs to help create a safe and contained environment where members feel able to freely express themselves without fear of judgement or consequence.

The data for this paper comes from three LPs, incorporating the views of 26 people from 15 different institutions (12 universities, 1 University College, and 2 other HE-related institutions). Each session began with the simple question 'what is it like to be a citizen of an academic institution in contemporary Britain?' from which discussions were allowed to evolve freely. The first LP was attended by 17 participants plus two external facilitators ${ }^{\mathrm{ii}}$; the second by 13 participants; and the third by seven. Eight people attended both of the first two events and three attended all three. Participants held different roles (professor, lecturer, researcher, etc.) in different institutions. They were not representative of all disciplines or of all kinds of HE institutions, although there was representation from across a wide range of disciplines (including sciences, arts, humanities, social sciences and business), institutional 
types (pre/post 92 universities, mission groups) and market position (as determined against university ranking, research profile and financial performance). In the sample of 26 there were 16 men, 8 non-UK nationals (estimated) and 7 professors.

Participants were recruited predominantly through the personal and professional networks of members of the research team (a not uncommon approach for listening posts see Dartington, 2000), with a snowball approach to identify additional participants (i.e. through the contacts of contacts). People who had responded to the online survey in Phase One of the larger project were also invited to attend where they were within easy access of the venue. Whist the first two LPs included a mixed sample of academics from different institutions; the third was convened with the explicit intent of gathering perspectives from academics in science disciplines in a single, research-intensive university. To this extent, the sample cannot be considered 'representative' (indeed there was bias towards social science disciplines and participants from HEIs in South East England) but nonetheless it incorporated a substantial degree of experience and diversity.

Handwritten notes were taken during the first two LPs and collated by one of the facilitators (an external in the first instance and a member of the research team in the second) into summary reports which were circulated to participants and researchers for comment. In the third LP, due to the relatively small group size and fast moving conversation, the discussion was recorded and transcribed in full. In each case participants were assured of confidentiality in the reporting of findings and, where possible, they were given the opportunity to withhold their institutional affiliation and role within group discussions. The overall themes described in this paper were identified from the summary reports and transcripts to highlight the most prevalent issues discussed across the three LPs.

The LPs were conducted over a period of six months from September 2010 to February 2011. This was a significant period within HE policy and practice in England given 
that the first occurred shortly before, and the second shortly after, the Browne Review of university funding (Browne, 2010). This review led to a change in funding of HE and the subsequent raising of the 'cap' on fees for UK/EU students from $£ 3,350$ to $£ 9,000$ per year. The third LP occurred following these changes and shortly before notification by universities of their proposed fee levels ${ }^{\text {iii }}$. Furthermore, LP2 occurred shortly after a series of high profile public demonstrations against the proposed increase in tuition fees (during which there was some public disorder with students at the forefront) and LP3 occurred shortly before a series of national strikes by members of the Universities and College Workers Union (UCU) over changes to the university pension scheme and working conditions.

\section{Results}

This section presents the six key themes identified across the three LPs. Illustrative quotes have been included where possible although whilst we indicate which LP they came from we have not endeavoured to provide further descriptors in order to: a) protect the identity of respondents, and b) to respect the interdependency of responses (as an outcome of group interaction rather than the views of a specific individual).

\section{Ambivalence and dissonance}

A theme that emerged within each LP was the sense of academic life as conflicted and ambiguous. The idea was particularly explored in the first LP where one participant introduced the term 'bipolar' to refer to the sense of experiencing contrasting emotions simultaneously. People felt both connected to and disconnected from their academic institutions and disciplines; empowered by their teaching and research, but alienated from power within the institution. Several participants expressed the need to balance apparently irreconcilable demands as illustrated in the following comments:

'You feel you have control over your time and yet a complete lack of control.' (LP1) 
'If you go to work you get lumbered with crap for which you don't get rewarded.

Other demands are put on me and I don't know how to balance them...' (LP1)

For at least one participant, these tensions were underscored by complex power relations, such as the one between teacher and student:

'What is rewarding is the freshness and optimism of the students, which is soon taken off them. I feel like Dracula, drinking from these students, it re-charges me.' (LP1)

When touching on this theme participants expressed a sense of dissonance or tension between different aspects of academic life which give rise to stress, dysfunction and ambivalence. It is something that is experienced as deeply troubling, unhealthy and largely irresolvable.

\section{Vulnerability and exclusion}

In each LP there was reference to a feeling of vulnerability - often associated with a sense of exclusion from key groups/constituencies within the institution. A part-time lecturer during LP1, for example, commented:

'I feel I don't belong anywhere, you are like a wanderer, with professional allegiances and other allegiances, it's hard to find your identity when you are part-time'. (LP1)

In LP2 a participant explained how at his/her institution the funding of academic posts is tightly linked to specific courses/modules and that there is insufficient preparation of people to move between them, thereby rendering them vulnerable to redundancy:

'[...] it's like being on the factory floor and just being trained to operate one part of the machinery.' (LP2)

A post-doctoral researcher in LP3 illustrated the particular vulnerability of those on fixed-term research contracts and the ways in which issues of inclusion and exclusion play out within day-to-day power dynamics. 
'They have this enormous army of people on grant money sitting in labs etc. [...] doing huge amounts of research, turning over huge amounts of money in research funding and at the end of your tour of duty when everyone's waiting cap in hand saying now where do I go they say "the exit's over that way - we've got six more people waiting for your desk".' (LP3)

These observations point to systemic power dynamics that disadvantage and marginalise particular groups that remain largely concealed to those outside the system.

\section{Opacity, inconsistency and critique}

Related to the previous issue was the sense that recognition and reward processes for academic staff are unclear and inconsistent. This theme was particularly explored in the third LP where one participant described their organisation as having 'a very strange, very prejudiced, very patronising, very opaque system.' Another participant at the same institution said:

'I think most academic appointments are based on nepotism [laughter] - I'd say 80 percent of them and there's a small percentage - let's say generously 20 percent - that may be genuinely based on merit.' (LP3)

Across all three LPs there was a sense that whilst institutions talk about the importance of teaching and service their recruitment and promotion processes almost exclusively privilege research ${ }^{\text {iv }}$.

'It frustrates me greatly that we employ people based purely on research and the funding that they've got, and then make them teach, whether or not they have any interest in teaching or are any good at teaching, and people who are good at teaching are penalised because they haven't done enough research and so we don't want them because they won't bring funding in.' (LP3) 
In LP2 two professors (both with formal management responsibilities) reflected on how, despite tenure and experience, they are still assessed according to research outputs. One asked 'at what point did I move from being the "bright young thing” to "another laggard"?' And, following some discussion about whether it is possible to trade power for respect, the other replied by saying that without a strong current research record ' $[\ldots]$ you just become an old person with no publications'.

Across all three LPs there was a sense that the 'rules of the game' are unclear and may well be manipulated by those in positions of power to their own ends. Furthermore, it was suggested the very nature of academic work, with its emphasis on critique, means that it is very rare to get recognition for good work and there is a constant pressure to prove oneself to colleagues, managers and self.

\section{Managerialism and autonomy}

In all three LPs participants expressed a sense that there is a strong managerial drive within universities that emphasises financial performance and brand over academic and social objectives. The role of professional administrators and their relationship to academics were debated and a concern expressed that they may be 'servants turned masters'. It was agreed, however, that academics may be partly responsible for this situation themselves in their tendency to withdraw from institutional governance.

'There is a theme here that people recruit administrators to do the admin work we don't want to do $[\ldots]$ we start off grateful and then find them creating things for us that we don't want to do [...] I feel guilty about it but it's a strategy of emotional management $[\ldots]$ there are hundreds of other people also doing it.' (LP2)

Alongside the culture of managerialism, however, there was a strong sense that experiences are moderated by line managers and the extent to which they support or not the 
activities of their staff. This was particularly the case for researchers on fixed-term contracts who expressed a dependency on the patronage of their supervisor.

'[...] my supervisor that I had for my doctorate who I got on very well with, he unfortunately without asking me got a professorship somewhere else, and you feel that you haven't got a protector now. I'm a bit adrift in that way [...] There is a lack of sense of justice there and if you haven't got a sense of justice and being treated justly you're not a proper citizen are you?' (LP3)

Within each LP there were also people who experienced this from the other side - i.e. those who experienced a degree of discretion in how they carry out their work and support junior colleagues. Generally it was felt that those who could thrive in this environment are people who run their own funded centres/projects and can operate largely independently of standard university systems and processes.

'You need to create a niche with its own funding/income stream.' (LP2)

'If thriving means that eighty percent of your time at work is a positive experience hold onto the things that nourish and interest you. Maybe it's not so much the work itself but the context in which it's done - a context of surveillance, measurement and control $[\ldots]$ jumping through hoops militates against thriving.' (LP2)

\section{Concern about changes in UK HE}

Participants in each LP expressed a sense of concern about how the changes outlined above are leading to a shift in the values and purpose of HE. There was a sense that the sector is heading towards a market economy where a relentless drive for student numbers and research outputs may detract from the core values of education and scholarship.

'There's a real sense that we're a business and our product is research and we sell research to whoever's got money.' (LP3) 
The concept of brand was discussed particularly in LP3, where it was suggested that the reputation of the organisation brings substantial competitive advantage in terms of attracting high quality students and staff.

'An institution like [this] is running to an extent on its reputation - the reason our graduates are very good is that our applicants are very good we don't really give them that much in between.' (LP3)

There was a sense across all three LPs that increased competition in the sector is driving out collegiality and collaboration within and between institutions. In consequence, it was suggested, there is a lack of a coherent voice representing the interests of the sector as a whole with each institution and/or mission group (Russell Group, 1994 Group, Million+, Guild HE, etc.) pursuing their own ends.

'There is a civil war in HE.' (LP2)

'There is a lack of leadership of the sector as a whole.' (LP2)

'Institutions are fighting against each other in this new landscape - there's no wider discussion about what's going on in HE.' (LP2)

\section{Citizenship and community}

Given the question that framed sessions, within each LP there was much debate about the extent to which participants felt themselves to be 'citizens' of HE. Many people expressed a sense of disengagement from their own institutions and a lack of clarity around organisation boundaries.

'I work around the institution, not in it.' (LP2)

'I'm not working on behalf of the institution - I'm working on behalf of me.' (LP3)

A sense of citizenship was expressed more often in relation to one's academic discipline and/or professional group. 
'Citizenship is determined in relation to my local community [...] rather than from my own organisation.' (LP2)

Despite this, there was not a strong sense of citizenship and community across the sector as a whole. Participants discussed the need to mobilise more effectively as citizens of HE in order to give voice and leadership to the sector more widely and to confront the many challenges that they face. Such an approach was perceived to carry both rights and responsibilities.

'Why are we withdrawing and disengaging as citizens? [...] I want to be able to engage with colleagues and to defend the university because it does things of which I'm proud.' (LP2)

'Citizenship is about rights and responsibilities [...] what are our responsibilities as citizens of UK HE?' (LP2)

Differences were noted between the experiences of people in different parts of the sector. For example, someone who spent time working in a Further Education college stated: 'I absolutely love my job, it is always evolving [...] I feel affiliated with [my institution] perhaps because of its strong vocational basis. There are lots of industry contacts, lots of staff come from industry, there is a shared background to draw on in teaching, research is done out of choice rather than necessity. I feel loyal to [my institution].' (LP2)

Similar 'counter views' were expressed by a minority of participants in each LP. As indicated earlier, these were generally people who worked at the periphery of the traditional teaching/research focus of HE - often those who ran their own projects/centres, had some discretion over budgets and were less rigorously scrutinised by 'research quality' indices.

\section{Discussion}


To summarise, the LPs solicited rich discussions about the nature of academic life and the experiences of participants. Whilst numerous issues were raised, these have been summarised under six themes: (1) ambivalence and dissonance, (2) vulnerability and exclusion, (3) opacity, inconsistency and critique, (4) managerialism and autonomy, (5) concern about changes in UK HE, and (6) citizenship and community.

These themes may be of little surprise to those who have worked within British universities in recent years and resonate with much prior research in the field (e.g. Becher and Trowler, 2001, Bolden et al., 2008, Clarke et al., 2011, Henkel, 2005, Middlehurst, 1993). Yet, whilst they may paint a rather pessimistic view of the sector, they also reveal an undercurrent of genuine passion and commitment to the values and purpose of HE. Examples were evident of where participants felt positive about their roles and the context in which they worked. Participants at each LP demonstrated a real concern about the manner in which their institutions and the sector as a whole appeared to be becoming fragmented and destructively competitive. They wanted to find ways to have more of a voice and engage in active debate about the changes in HE and how to stay true to academic values. They expressed a desire to find ways to participate more actively in the civic life of their institutions and the communities that surround, feed into and support them.

It may be suggested that these reflections invoke an idealistic conception of citizenship that is both unrealistic (given the highly competitive, resource-constrained context of UK HE) and unachievable (given the nature of power and politics in organisations and society). Whether or not this is the case, however, they do illustrate some 'preoccupations' of UK academics that hold important implications for how we think about and approach leadership, management and governance within universities.

Firstly they suggest that the increasingly 'executive', 'corporate' and 'managerial' ways in which leadership and management roles are framed within UK HE institutions may 
accentuate academic disengagement from such activities. This is problematic given the fact that much evidence (e.g. Bryman, 2007, Goodall, 2009) highlights the centrality of academic reputation and credibility in the effective running of universities and the fact that many institutions are concerned about the shortage of people putting themselves forward for such roles. The result has been an increasing shift from elected to appointed leaders and fixedterm to permanent roles (with associated financial and other incentives). As universities have consolidated schools and departments into larger business units (believed to be better able to respond to fluctuations in market demand and government policy) they have recognised a need to 'professionalise' their financial, marketing and support processes. In order to do this they have recruited increasing numbers of professional staff with qualifications and experience considered appropriate to this new definition of the task (Whitchurch, 2008) and streamlined allegedly cumbersome and inefficient processes such as the committee structure. Unfortunately, however, despite a rhetoric of ‘distributed leadership' (Bolden et al., 2009, Gosling et al., 2009) many academics have felt themselves sidelined rather than embraced within the governance and running of their institutions (Macfarlane, 2011, Rayner et al., 2010).

Secondly, these findings imply the importance of a sense of shared identity and belonging to an identifiable community in terms of motivating academic staff to take an active role in, and responsibility for, leadership, management and governance activities. Academics are often actively involved in scholarly and practitioner activities outside their institutions (such as editing journals, chairing research panels, coordinating seminars and events, engaging with employers and policy makers, etc.) yet this contribution is seldom explicitly recognised and rewarded within their own institutions. A sense of disengagement and disconnect from their own institutional communities erodes commitment to principles of 'academic citizenship' and 'collegiality'. University performance metrics tend to promote a 
rather individualistic approach that may undermine commitment to the development of a future generation of academics and leaders (Greenberg, 2006).

Thirdly, the issues raised during the LPs illustrate a perceived lack of transparency in leadership and management processes within many institutions, underpinned by inconsistent and non-meritocratic approaches. In LP3, for example, the continued importance of patronage and the barter and exchange of favours was highlighted (particularly in relation to the status of contract research staff and those in part-time posts). In LP1 there was talk about the 'rules of the game' and a sense that they are largely tacit and highly variable. Whilst such dynamics are unsurprising in such large and complex organisations they fuel speculation and distrust.

Fourthly, the LPs imply that whilst institutions may be endeavouring to enhance their own leadership and management processes very little attention is given to leadership of the sector. The most active parties in this respect are the various university mission groups, although each of these has their own agendas and tend to compete with one another rather than endeavouring to find a voice for the sector as a whole. Universities UK is the one organisation with a remit to represent UK HE more generally yet it has come under quite a lot of criticism from academics and the public for failing to effectively challenge recent government reforms (Mroz, 2010). It has, arguably, positioned itself as a representative of the employers (casting academics as employees) and as such is unlikely to represent academics qua academics, but as 'human resources'.

Finally, and perhaps most critically, this research has illustrated the conflicted and ambiguous nature of academic life. The term 'bipolar', as used by one participant, captures well the paradoxical tensions faced many UK academics in relation to the various aspects of their role and how they are assessed. The potential impact of prolonged exposure to such pressures on psychological and organisational health and wellbeing is something that calls for 
institutional leaders to take note. In a culture where academics are torn between competing agendas, identities and allegiances it is perhaps unsurprising that staff report significantly higher levels of work-related stress and significantly lower levels of organisational commitment than comparator groups (Kinman and Jones, 2003, Tytherleigh et al., 2005). The sustainability of a system based on such imbalances is precarious and something that threatens the long-term security of UK HE as a whole.

So how might we conceive of a response to these trends? In his book Against Management Martin Parker (2002) suggests that 'management' is just one possible approach to the challenge of 'organising'. He argues that managerial approaches conflate 'control' with 'ordering' and suggests that it is possible to conceive of other ways of organising work, based for example on 'co-ordination, co-operation, barter, participation, collectivity, democracy, community, citizenship' (ibid: 11). McLean (2006) suggests that such approaches resonate with academic ideals and would be well suited to the organisation of work within universities where people carry multiple roles and responsibilities such as 'academic' and 'manager', 'teacher' and 'researcher', etc. Parker's own account of taking on the role of Head of Department, however, graphically illustrates how such roles tend to be framed in ways that leads to them being experienced as conflicting rather than complementary (Parker, 2004). He suggests, however, that whilst the call to a managerial approach to organising is powerful it is not inevitable - 'I still believe', he concludes, 'that organizing (of universities, or anywhere else) can be much more polymorphous than one best way market managerialism might assume' (ibid: 55).

The notion of academic citizenship outlined at the beginning of this paper offers one potential alternative to equating leadership responsibilities with management roles. The tendency to individualise leadership by associating it with particular roles may be a poor replacement for the idea of leadership as the collective responsibility of a community of 
engaged citizens (Thompson et al., 2005). Rather than investing so much time and effort developing 'leaders' in HE perhaps we would benefit from endeavouring to enhance people's sense of belonging, out of which should arise an enhanced sense of citizenship and a corresponding desire to engage in community life. Rather than just assessing individual performance against workload allocation models and research outputs perhaps more attention could be paid to recognising and rewarding organisational citizenship behaviour (Organ, 1988) that glues and binds organisations together.

It is important, however, not to romanticise the notion of citizenship, particularly within a context such as the UK where associated concepts such as the 'Big Society' and 'Distributed Leadership' have been employed in instrumental ways to drive public sector reform (see, for example, Grint and Holt, 2011, Hall, 2011). From our experience of the LPs within the current project, however, asking academics to consider their experiences from a position of citizenship surfaces a different kind of discourse. The concept of citizenship, it would appear, triggers a more emotive response in which participants can begin to recognise their own part within power relationships and find ways of articulating their anxieties about academic life. Identifying as 'citizens' evokes ideals and feelings associated with belonging to a collective defined, not by organisational goals and outputs but by community membership; drawing attention to responsibilities and duties as well as rights and obligations.

Returning to the psychoanalytic dimension of the LP methodology, it could be argued that the discussions surfaced a number of unconscious aspects of academic life, including an ambivalent (almost love-hate) relationship with one's academic work and institution (see also Clarke et al., 2011); a collusion in the growth of managerialism; and anxiety about career progression and success. Indeed, the findings resonate with Sievers' (2008) account of the 'psychotic university' in which trauma is regarded as the inevitable consequence of institutional reform (often dismissed as 'collateral damage' by those in managerial roles). 
Sievers, writing about German HE but equally applicable within the UK, suggests that university reform (1) 'fosters an organizational culture dominated by a totalitarian state of mind', (2) is underpinned by a guiding paradigm of 'economic value and practices', (3) 'is partly founded on magic thinking', and (4) 'is characterized by the view that knowledge, rather than thinking and understanding, is primary' (ibid: 242).

Whilst Sievers focuses on the implications for people in managerial roles our research illustrates the impact on those in non-managerial roles (or who are responding from their role as 'citizens' rather than as 'managers' or 'employees'). Together these accounts highlight the ease with which both sets of actors can become caught in a cycle of dysfunction - as Sievers argues: 'the more the pressure, the more likely the psychotic dynamic will increase and that managers - like other organizational role holders - will become caught in their own individual psychotic parts' (Sievers, 2008: 243).

Although it may be suggested that managerialism has become so deeply ingrained within universities that it has diminished the capacity for critical thought and collective action, Henkel (2005) comes to a somewhat different conclusion. In her research in the UK she illustrates how concepts of academic identity and autonomy can be used to engage with managerialist agendas in ways that may bring some advantages to the incumbents and their organisations. In our own study, the ability expressed by a number of LP participants to find a niche, somewhat protected from organisational performance management regimes, supports the view that it may occasionally be possible to divert managerial agendas to one's own advantage where some other form of power or influence is available. Such a response, however, tends to be marked by a retreat from identification with the organisation in favour of a more isolated 'tribe' (Becher and Trowler, 2001) and a subsequent narrowing one's sense of citizenship and responsibility to a wider constituency. 
Power and influence arise from many sources, of which formal managerial position is just one. Despite this, when organisations (universities and others) claim that they need better or more leadership they are generally referring to leadership of the institution, with most attention directed at how to improve productivity and reputation. The findings from the LPs, however, also highlight the importance of leadership of projects (funded or not), of academic disciplines, of public opinion, of communities, of the sector as a whole, and even of resistance to managerial, political and other reforms. Unsurprisingly these domains of leadership practice may at times come into conflict with one another and their relative success or failure is assessed in different ways. Organisational leaders, in HE as elsewhere it seems, frequently attempt to silence such debates and, in so doing, may well marginalise the very kind of critical debate that their academic colleagues expect.

Whilst the research outlined in this paper intentionally focussed on citizenship rather than leadership it illustrates a number of features of the academic landscape that are important for HE leaders and managers to understand. Taken together our findings suggest potential benefits of creating space for reflexive dialogue about the purpose and aims of HE and for sharing experiences, not as managers and subordinates, but as citizens and peers. For many of the participants in our research, the LPs were experienced as cathartic - an opportunity to engage with fellow academics on a human level that is rarely experienced during day-to-day work. Whilst such exchanges may not resolve the challenges of a conflicted existence they may help provide a chance to work through and potentially reassess the multiple and competing agendas facing people in academic roles in UK HE.

An example of the potential for a leadership approach based on critique and debate is given in Neary and Saunder's (2011) project on learning landscapes in HE. They suggest that rather than leaving the design of teaching and learning spaces to 'professionals', great value can arise from incorporating critical pedagogy as a key framework for such initiatives. An 
approach based on academic debate and critique, it is argued, connects with core academic values; results in greater levels of ownership and commitment; and leads to the development of better, more functional, learning spaces.

\section{Conclusions}

This paper has suggested that (re)focussing attention on the role of citizenship within HE may help respond to some of the perceived tensions that a managerial approach to leadership in universities has produced. Engaging from a position as 'citizens', rather than as 'leaders', 'managers' or 'employees', may foster a greater appreciation of the commonalities of academic experiences and give rise to a more collective and community-based response.

We have presented the listening post approach as a potential methodology for considering academic leadership from a social rather than an individual or organisational perspective. Whilst this, on its own, is not a replacement for other perspectives we suggest that it offers a space for a different kind of discourse that exposes the 'dialectical' nature of leadership (Collinson, 2005), and recognises the inherent ambiguities and complexities of academic life rather than masking them through standardised managerial practices.

Clearly the findings presented in this paper are based on a small sample and would benefit from further exploration, including incorporation of the views of 'non-academic' staff that play a significant role in the life of academic institutions. It would also be interesting to conduct comparative research in other societies - including different countries, as well as different professional groups - in order to explore the similarities and differences between the experiences of UK academics and their counterparts elsewhere.

For those of us working in the sector this research poses questions about how to nurture a culture of critique and scepticism of the power dynamics that directly impact upon our lives as citizens of HE, and should encourage us to experiment with other forms of organising that may reduce some of the toxic effects of ambivalence and enhance our sense 
of collective endeavour. It should also, however, remind us to remain wary of how concepts such as 'leadership' and 'citizenship' can become hijacked by instrumentalist agendas, and highlight the need for continued reflexivity and open debate on the nature and purpose of HE.

\section{References}

Albert, S. and Whetten, D. (2004) Organizational Identity. In: M. J. Hatch and M. Schultz (eds.), Organizational Identity: A Reader. pp. 89-118. Oxford: Oxford University Press.

Bargh, C., Scott, P. and Smith, D. (1996) Governing Universities: Changing the Culture?, SRHE and OU Press, Buckingham.

Becher, T. and Trowler, P. R. (2001) Academic Tribes and Territories (2nd edition), SRHE/Open University Press, Buckingham.

Bennis, W. (2007) 'The challenges of leadership in the modern world: An introduction to the special issue', American Psychologist, 62(1), pp. 2-5.

Beverungen, A., Dunne, S. and Sørensen, B. (2008) 'University, failed', Ephemera: theory \& politics in organization, $\mathbf{8}(3)$, pp. 232-237.

Bolden, R., Petrov, G. and Gosling, J. (2008) 'Tensions in higher education leadership: towards a multi-level model of leadership practice', Higher Education Quarterly, 62(4), pp. 358-376.

Bolden, R., Petrov, G. and Gosling, J. (2009) 'Distributed leadership in higher education: rhetoric and reality', Educational Management, Administration and Leadership, 37(2), pp. 257-277.

Browne, J. (2010) Securing a Sustainable Future for Higher Education: An independent review of higher education funding \& student finance. URL: www.independent.gov.uk/browne-report, accessed 26/11/2010. 
Bryman, A. (2007) 'Effective leadership in higher education: a literature review', Studies in Higher Education, 32(6), pp. 693-710.

Clark, B. R. (1998) Creating Entrepreneurial Universities: Ogranizational Pathways of Transformation, Pergamon, Oxford.

Clarke, C., Knights, D. and Jarvis, C. (2011) A Labour of Love? Academics in Business Schools. 7th International Critical Management Studies Conference (CMS7). Naples, Italy.

Collinson, D. (2005) 'Dialectics of leadership', Human Relations, 58(11), pp. 1419-1442.

Cunliffe, A. L. and Eriksen, M. (2011) 'Relational leadership', Human Relations, 64, pp. $1425-1449$.

Dartington, T. (2000) The Preoccupations of the Citizen: Reflections from OPUS listening posts, OPUS, London.

Deem, R., Reed, M. and Hillyard, S. (2007) Knowledge, Higher Education, and the New Managerialism: The Changing Management of UK Universities, Oxford University Press, Oxford.

Drath, W. H., McCauley, C. D., Palus, C. J., Van Velsor, E., O'Connor, P. M. G. and McGuire, J. B. (2008) 'Direction, alignment, commitment: Toward a more integrative ontology of leadership', The Leadership Quarterly, 19(6), pp. 635-653.

Goodall, A. (2009) Socrates in the Boardroom: Why Research Universities Should be Led by Top Scholars, Princeton University Press, Princeton.

Gosling, J., Bolden, R. and Petrov, G. (2009) 'Distributed leadership in higher education: What does it accomplish?' Leadership, 5(3), pp. 299-310.

Greenberg, M. (2006) 'The power of academic citizenship', The Chronicle of Higher Education, 52(22), p. B20. 
Grint, K. and Holt, C. (2011) 'Leading questions: If 'Total Place', 'Big Society' and local leadership are the answers: What's the question?' Leadership, 7(1), pp. 85-98.

Hall, D. (2011) The appropriation of the participatory by the instrumental: The regulation and management of teacher identities in England. 7th International Critical Management Studies Conference (CMS7). Naples, Italy.

Henkel, M. (1997) 'Academic Values and the University as Corporate Enterprise', Higher Education Quarterly, 51(2), pp. 134-143.

Henkel, M. (2005) 'Academic identity and autonomy in a changing policy environment', Higher Education, 49(1), pp. 155-176.

Kennedy, B. D. (1997) Academic Duty, Harvard University Press, Boston.

Khaleelee, O. and Miller, E. J. (1985) Beyond the small group: society as an intelligible field of study. In: M. Pines (ed.) Bion and Group Psychotherapy. pp. 354-385. London: Tavistock/Routledge.

Khurana, R. (2007) From Higher Aims to Hired Hands: The social transformation of American business schools and the unfulfilled promise of management as a profession, Princeton University Press, Princeton, NJ.

Kinman, G. and Jones, F. (2003) "Running Up the Down Escalator': Stressors and strains in UK academics', Quality in Higher Education, 9(1), pp. 21-38.

Lawrence, W. G. (1980) Citizenship and the work place: a current case study. In: B. Sievers and W. Slerssina (eds.), Arbeitspapier des Fachbereichs Wirtschaftswissen der Gesamthochschule (Wuppertal), No. 44.

Macfarlane, B. (2005) 'The Disengaged Academic: the Retreat from Citizenship', Higher Education Quarterly, 59(4), pp. 296-312. 
Macfarlane, B. (2007) 'Defining and Rewarding Academic Citizenship: The implications for university promotions policy', Journal of Higher Education Policy and Management, 29(3), pp. $261-273$.

Macfarlane, B. (2011) 'Professors as intellectual leaders: formation, identity and role', Studies in Higher Education, 36(1), pp. 57-73.

Marshall, T. H. and Bottomore, T. (1992) Citizenship and Social Class, Pluto, London.

McLean, M. (2006) 'Them and Us?' Illuminato, Spring 2006.

McNay, I. (1995) From the collegial academy to corporate enterprise: the changing cultures of universities. In: T. Schuller (ed.) The Changing University? Buckingham: SRHE and OU Press.

Middlehurst, R. (1993) Leading Academics, SRHE and OU Press, Buckingham.

Middlehurst, R. (2008) 'Not Enough Science or Not Enough Learning? Exploring the Gaps between Leadership Theory and Practice', Higher Education Quarterly, 62(4), pp. 322-339.

Molesworth, M., Scullion, R. and Nixon, E. (2011) The Marketization of Higher Education and the Student as Consumer. Abingdon: Routledge.

Mroz, A. (2010) 'Leader: Short-term relief, long-term grief', Times Higher Education, 2nd

\section{December.}

Neary, M. and Saunders, G. (2011) 'Leadership and learning landscapes: the struggle for the idea of the university', Higher Education Quarterly, 65(4), pp. 333-352.

OPUS (2010) Listening Posts - An Introduction. http://www.opus.org.uk/lstngpst.htm, accessed 01/08/2010.

Organ, D. W. (1988) Organizational Citizenship Behavior: The Good Soldier Syndrome, Heath and Company, Lexington, Massachusetts/Toronto D.C. 
Parker, M. (2002) Against Management: Organisation in the Age of Managerialism, Polity Press, Cambridge.

Parker, M. (2004) 'Becoming manager or, the werewolf looks anxiously in the mirror, checking for unusual facial hair', Management Learning, 35, pp. 45-59.

Rayner, S., Fuller, M., McEwen, L. and Roberts, H. (2010) 'Managing leadership in the UK university: a case for researching the missing professoriate?' Studies in Higher Education, 35(6), pp. 617-631.

Sievers, B. (2008) 'The psychotic university', Ephemera, 8(3), pp. 238-257.

Stapley, L.F. (2006) A large system intervention: the influence of organisational culture. In L. J. Gould, L. F. Stapley and M. Stein (eds) The Systems Psychodynamics of Organizations: Integrating the Group Relations Approach, Psychoanalytic and Open Systems Perspectives. pp 157-174. London: Karnac Books.

Tajfel, H. and Turner, J. C. (1979) An integrative theory of intergroup conflict. In: W. G. Austin and S. Worchel (eds.), The Social Psychology of Intergroup Relations. pp. 3347. Monterey, CA: Brooks/Cole.

Thompson, P., Constantineau, P. and Fallis, G. (2005) 'Academic citizenship: An academic colleagues working paper', Journal of Academic Ethics, 3, pp. 127-142.

Turner, J. C. (1985) Social categorization and the self concept: A social cognitive theory of group behaviour. In: E. J. Lawler (ed.) Advances in Group Processes, vol 2. pp. 77122. Greenwich, CT: JAI Press.

Tytherleigh, M. Y., Webb, C., Cooper, C. L. and Ricketts, C. (2005) 'Occupational stress in UK higher education institutions: a comparative study of all staff categories', Higher Education Research \& Development, 24(1), pp. 41-61.

Uhl-Bien, M. (2006) 'Relational leadership theory: exploring the social processes of leadership and organizing', The Leadership Quarterly, 17, pp. 654-676. 
Whitchurch, C. (2008) 'Shifting identities and blurring boundaries: the emergence of 'third space professionals' in UK Higher Education', Higher Education Quarterly, 62(4), pp. 377-396.

\footnotetext{
${ }^{i}$ Also referred to as 'listening groups' (Stapley, 2006 )

${ }^{\text {ii }}$ In fact this event was facilitated by Tim Dartington and Olya Khaleelee who jointly developed the listening post method. We are grateful for their contribution to this project.

iii Shortly afterwards universities announced their fee decisions, with over two thirds opting for the maximum fee, despite politicians having suggested that most universities should not charge any more than $£ 6,000$.

iv This was particularly true in traditional 'research-intensive' universities but also increasingly the case within post-92, 'teaching focussed' institutions.
} 